\title{
SIMPOSIO PERMANENTE SOBRE
LA UNIVERSIDAD
}

Alfonso Borrero C., S.J.

Director del Simposio Permanente Sobre la Universidad

\section{CONFERENCIA XL PROSPECTIVA UNIVERSITARIA}

\section{PRIMERA PARTE EL PROYECTO DE LA UNIVERSIDAD FUTURA}

Entendamos el futuro como algo que ya se hizo presente entre nosotros. Y las proyecciones, no como pliego en blanco y aún por dibujar, sino proyecto tangible cuyas líneas ya están en construcción, obra de nuestra mano artífice en gestión universitaria. Aceptemos que el futuro que nos pune a pensar, llegó ya y vive con nosotros. Que lo estamos haciendo. Que no nos espera prehecho por determinismos de la historia y como asaltante en las vueltas del camino por andar.

De manera que no hablaremos aquí de La Universidad del Siglo XXI como si se tratara de un posesivo o poseído que está por hacerse. De algo que otros construi- rán para ellos y que nosotros vaticinamos inoperantes. No es lo mismo pensar en la Universidad de manera halagüeña pero improductiva, que pensar la Universidad para hacerla con la eficacia de los verbos activos.

Prefiramos, para ser realistas y eficaces, el verbo pensar como gestor de acciones que edifiquen la Universidad hacia el futuro siglo XXI, porque haciendo nosotros rumbo al navegar, el futuro es un presente en gestación. Estamos ya construyendo el futuro con nuestra actividad universitaria. Si bueno o malo, de nosotros depende, y ¡depende desde hoy! 
Ni diremos en esta Conferencia nada que no hayamos afirmado. Nada distinto a la materia reciente de este Seminario General del Simposio Permanente sobre la Universidad. Nada diferente Je cuanto hemos traído en manos del estudio, de lo que estamos haciendo o estamos dispuestos a llevar a cabo, nuevo y mejor. Sólo que nuestro presente hacer universitario y el jlo haremos! entusiasta, se sume ahora en el hondón fecundo de nuestras reflexiones y conocimientos, de que carecíamos, sobre el ser, el quehacer y el cómo hacer diligente de la universidad.

Aquí se destila la quintaesencia de nuestro Seminario.

+ Conduciremos estas reflexiones -operativas, no sólo proyectivascomo quien lanzó una piedra sobre el agua tranquila, y estudia con cuidado los efectos en la celeridad vibrante, movediza y simultánea de los círculos que se alejan del centro común, mientras se desplazan por la superficie y fondo de los niveles superiores de la educación. En concreto, de la Universidad.

Cada uno de los círculos de reflexión que ahora emprenderemos, es desplazamiento concéntrico de nuestra mente que piensa y hace, aligerada con remembranzas de la historia. Pues si ella discurre con el tiempo y en el tiempo, nada podremos predecirle ni en ella producir que no cuente con los impulsos del pasado. Llegados hasta nosotros los electos de la historia, ellos $\mathrm{m} r$ nuestro presente, y condición para zanjarle desde ahora los rumbos venideros a la Universidad En pensamiento de San Agustín, el tiempo es un triple presente: el pasado que es memoria presen- te, el presente que es experiencia actual, y el futuro que es ya expectativa y a la vez presencia del porvenir. La historia buena es acción de las libertades responsables. Y cuanto la Universidad sea en el futuro, será fruto de los universitarios de hoy.

Advirtamos cómo nos divierte reiterar en formas varias el mismo pensamiento: El futuro de la Universidad se encuentra ya anticipado en nuestras manos. Aparentemente poseedor de ilimitadas posibilidades, pero en realidad sumiso al cercado estrecho o ancho de nuestra posesiones culturales. De ellas y de modo ineluctable devanaremos el porvenir universitario, sin por ello pensar que le son ajenas a nuestra responsabilidad actual postularle al aún intangible futuro los rasgos deseados y, desde ya, obrar en consecuencia. El futuro es a la vez continuidad y creación. De las similitudes, somos los vehículos y de lo nuevo y diferente ya somos I arcadores. Si herederos de valores culturales sobre los cuales tiene derecho el futuro en gestación para hacerlos suyos, también somos artífices de la cultura que debemos legarles a los tiempos por venir, enriquecida e incrementada. 


\section{Primer círculo de reflexión: Los modelos universitarios}

Comencemos el andar de nuestras reflexiones con breve recuento de la historia, a propósito de los estilos, modelos, cortes o modos de ser universitarios que nacieron a partir de 1800.

+ Es de sabido consenso que pese a las convulsiones habidas con ocasión de las reformas protestante y católica, y al lento aclimatarse de las universidades al impacto de la Revolución Científica, del orgullo ilustrado, y de la industria subsiguiente; la Universidad fue muy idéntica a sí misma hasta el ingreso del siglo XIX.

Pero a partir de aquella cifra del tiempo, significativa por su cauda de dos ceros, hubo abundancia de ojos puestos sobre la Universidad y manos interventoras que dieron formas diferentes y no siempre libres de abusivo capricho, a la institución suprema del saber.

Los historiadores iniciaron o multiplicaron esfuerzos por indagar la historia de la Universidad, al paso que unidos a otros pensadores le esclarecían sus notas históricas de corporación científica, universal y autónoma y sus misiones y funciones fundamentales en orden al hombre, la ciencia, y la cultura. Así nacieron diversas filosofías universitarias, acordes, según los casos, con el interés particular de los estados modernos que llegados del largo camino de su conformación desde los siglos del Renacimiento, entraban a la centuria decimonónica bien convencidos y percatados de cuanto la institución superior podría reportarles en beneficio del poder nacional: científico, político, administrativo, social, económico y aun militar. Tal es la génesis de los estilos o modos de ser universitarios nacionales. 
Que si el napoleónico, más con leyes que inspirado en principios y anheloso de situar la Universidad, profesionalizada, al servicio funcional del Imperio que el corso magnífico labraba con las leyes y la espada: nada de investigación, tarea ajena a la Universidad y puesta en manos de las Academias. Que si el modelo alemán, fruto del pensar filosófico pendiente de la investigación científica innovadora para enaltecer y fortalecer el imperio prusiano. Que si el británico, tan selectivo para esculpir en cultura al gentleman conductor de la sociedad.

Después, hijo de cruce sanguíneo entre la tradición universitaria inglesa y germana, el modo de ser democrático que empezara a concebir Jefferson para Norteamérica, muy pagado de la utilidad de la ciencia para el progreso económico. Y pariente por descendencia de lo francés y lo alemán, la universidad rusa de la omnipotente Catalina, corte universitario que de vendí s soviético, moldeado en la fragua mental de Lenin después de la Revolución de Octubre.

+ Estos son y aún subsisten, modificados es cierto por influjos mutuos, los estilos clásicos de la universidad que germinó y creció en el siglo XIX, y en el XX confirmó su pentagonal efloración. En Latinoamérica, a las tradiciones universitarias salmantinas y alcalainas del Renacimiento, se les unieron bien pronto la forma napoleónica y después de la segunda Guerra el influjo norteamericano. De Alemania, poco directo nos llegó, y estuvo entre nosotros la nota soviética por efluvios estudiantiles, profesorales y aun directivos de la Universidad de la Amistad de los Pueblos, la Patricio Lumumba de Moscú, fundada en 1960.

+ No puede la universidad mundial dejar de lado sus ascendientes históricos y filosóficos. Ni la América Latina las condiciones previas, si de veras desea trazarse su filosofía hacia el futuro, reteniendo de aquí, trayendo e incrementando de allá, fortaleciendo lo propio que tenga bueno y disuadiéndose con decisión de lo exótico malo. Nuestra filosofía, digo, porque ser m ahora los fundamentos de nuestra Universidad hacia el siglo XXI, no es simple operación mecánica y administrativa, como muchos planificadores piensan, sino introducirle a la Universidad principios conductores que nos dejen la satisfacción de labores educativas bien cumplidas. 
+ Volvemos, pues, a los modelos clásicos de universidad, de los cuales, insisto, no prescindimos porque sus genotipos discurren hoy, confundidos en veces pero actuantes, por el torrente sanguíneo de la universidad mundial.

Estos modelos, a más de lo dicho, difieren por la mayor o menor sumisión, en cada uno. El poder de la ciencia bajo el poder político y del poder epistemológico al arbitrio del mandato por el grado en que cada estilo universitario y sus seguidores hayan propiciado la dependencia del hombre respecto a la ciencia que él creó, y por la forma en que cada modelo se haya interesado por hacer al hombre gestor de su propia cultura y de su sociedad, o haya convertido Universidad en una función del aparato estatal.

Es, en suma, la diferencia que Paul Ricoeur dejó sentada entre las universidades de la idea -la alemana, la inglesa y la norteamericana-, y las universidades función utilitarista en manos del Estado: la francesa y la soviética desconocedoras, con menor o mayor instancia, de las líber q del espíritu y del poder del saber.

Sin embargo, todos los cinco estilos bien pueden haber olvidado que !a persona es el su natural del derecho a educarse, y que el hecho educativo tiene el deber primario de orientarse a la persona para su vida en sociedad. A la persona que no puede ser subyugada y destruida por el poder de la ciencia que ella crea.

Pueden los estilos universitarios haber dejado en los rescoldos del olvido que "el hombre en su realidad singular tiene una historia propia de su vida y una historia propia de su alma", según expresión de Juan Pablo II en la Redemptor Hominis. O como Unamuno a los estudiantes salmantinos: "No se crea cada uno de vosotros ni más ni menos, ni igual que otro cualquiera, que no somos los hombres cantidades".

Conclusión de este primer círculo de pensamiento: que hacia el hombre debe tender primordialmente la filosofía universitaria del futuro, para que el hombre sea el señor de la ciencia -no su súbdito y víctima-, gestor de la cultura y del orden en la sociedad. 


\section{MISIONES Y FUNCIONES DE LA UNIVERSIDAD: LA PERSONA, LA CIENCIA, LA SOCIEDAD, EL ESTADO}

Bien está que la ciencia y los conocimientos sigan siendo asumidos como función de la Universidad para recogerlos, conservarlos, transmitirlos; investigarlos y adelantar sus fronteras; aplicarlos utilizarlos en beneficio de la sociedad y para incrementar la cultura científica. Pero la cultura científica, en el sentido estrecho que hoy se le abona, no es ni puede ser la totalidad de la cultura, con dejación al soslayo de los restantes valores. El hombre no es sólo ciencia y profesión. Es ante todo trabajo constructivo.

+ Y acertado que la Universidad hacia el futuro tome como responsabilidad suya el desarrollo de la sociedad, función de importancia indiscutible si el desarrollo es pleno e integral, ajeno a recortadas porciones de desarrollismos parciales.

+ Acatable, en fin, que la Universidad sirva al Estado y se someta a sus orientaciones, mas nunca hasta el extremo de ser subyugada ni sometida al arbitrio del funcionario pasajero.

\section{Segundo circulo de reflexión: Equilibrio de funciones}

Es evidente que ninguno de los modos de ser universitario pudo haberse entregado por entero y de modo exclusivo, disyuntivo y legítimo, a las misiones de formar al hombre, a la producción de ciencia, y al desarrollo de la sociedad y sustento del Estado. Hubo y hay en cada uno de ellos, acentos dominantes, no monólogo instrumental. Persona, ciencia y sociedad, son actores en el drama de la vida real y del acontecer universitario.

Pero no podemos ignorar que la investigación científica y la cara visible de la ciencia, la tecnología y su uso político y económico, han llegado a ser acentos y preferencia casi exclusiva, en algunos casos, de la Universidad, dominantes sobre los que dicen con la auténtica formación de la persona el desarrollo justo y equilibrado de las sociedades humanas.

Angustiados por el subdesarrollo económico, Universidades del Tercer mundo, y los Estados, parecen inclinarse a recortar la 
distancia tecnológica que los separa de los $r$ avanzados, a expensas de todo otro valor, aun de aquellos que si bien tenidos en cuenta evidencian que las distancias no existen. Que los méritos y virtudes ensombrecidas bajo la pobreza, encumbrarían no pocos países por encima de los campeones del desarrollo unilateral y pragmático.

LA PERSONA

LA CIENCIA Y LA CULTURA

LA SOCIEDAD Y EL ESTADO
Conclusión de este círculo reflexivo, es la equilibrada acción de las funciones universitarias; de manera que pues: hombre como interés cimero, sin soslayar la ciencia y los beneficios que de ella reportamos, la ciencia y la tecnología contribuyan al desarrollo de la sociedad.

Equilibrio de funciones y aspiraciones, con la persona -Prima inter pares- sobre la sociedad y la ciencia. Pues sin la persona y la sociedad no existiría; y corno gestora que es del saber, está llamada a señalarle sus destinos, lo mismo que a la sociedad.

\section{Tercer círculo de reflexión: Las urgencias o apremios universitarios}

Persona, ciencia y sociedad y el todo de la cultura, son misiones y funciones universitarias frecuentemente expresadas con la correspondiente trilogía: docencia, investigación y servicio. Mas para efectos del mejor equilibrio en la acción y el anhelo, hoy se habla de urgencias, apremios y actitudes imperativas que remodelan las herencias universitarias recibidas del siglo XIX y de los decenios que van corridos de la presente centuria.

Estas urgencias son la conciencia crítica, la conciencia política y la conciencia nacionalista o cultural. Al respecto, nuevamente Paul Ricoeur: La Universidad de hoy está triplemente urgida por la responsabilidad de la discusión política como un caso particular de la crítica teórica y práctica de la vida cotidiana, a fin de asumir el problema de la doble cultura universitaria y no universitaria del intelectual moderno. 
No se crea que se trata de algo nuevo y nunca visto en la vida de las universidades. Si de renacida conciencia. Ni de tres misiones y funciones más que se agregan a las consabidas de la persona, la ciencia y la sociedad. Son actitudes renovadas que someten a severo examen los desequilibrios en que la institución universitaria pudo haber caído por sobreponderar una, en desmedro de las otras ineludibles responsabilidades.

+ Paul Ricoeur, al presentar tres urgencias, se refiere a ellas como instancias racionales. Sin embargo, bien sabemos que en el renacer de estos tres vocablos -renacer, digo, porque ellos no habían sido ajenos al desarrollo de la universidad histórica-, asumieron sentido y contenidos varios, y en no pocas veces respondieron a actitudes emotivas del individuo o de la masa.

-Así, la urgencia o actitud crítica, llamada al acatamiento de principios fundados en la ética social e individual para juzgar racionalmente los efectos de la ciencia sobre la sociedad y sobre la persona, tuvo, sin embargo, su opuesto pendular. Y por urgencia crítica se entendió la acción revolucionaria y desechadora de lo existente, incluso destructora de la Universidad.

- La urgencia o actitud política reaccionó contra la sumisión del poder del saber a las decisiones políticas, y mucho más cuando las tales decisiones vinieron instigadas por propósitos bélicos. Responder debe entonces la Universidad con posturas racionales, como el desarrollo y el estudio honesto de las ciencias sociales, un tanto ensombrecidas por la eminencia descollante de las ciencias naturales; con la actitud responsable del individuo ante sus deberes ciudadanos, y con la búsqueda de mejores acuerdos del poder del saber y del poder político, hacia un humano concepto del desarrollo social que venga revestido del nombre de la paz.

Con todo, en no pocas ocasiones la opción política universitaria derivó en la entrega de la universidad como tal a la acción electorera y partidista, cuantas veces la institución aceptó someterse a conducciones exógenas e interesadas. También se prestó de alcahueta fácil para la violencia y el atropello.

-Finalmente, la urgencia o apremio nacionalista hubo de ver con la actitud de la persona ante la cultura, agente y cuna de la nacionalidad. Nacionalidad y cultura se consideraban lesionadas, lesionables o lesionantes, por la transferencia tecnológica, importada o exportada. 
Al fenómeno natural de la internacionalización de la ciencia en la época contemporánea se lo quiso esquivar, imprimiéndole a la ciencia gentilicios que no le avienen, y rechazándola como una mercancía etiquetada en el país de procedencia. Igualmente se rechazó la cara visible de la ciencia, la tecnología, por juzgarla injusta invasora del alma nacional. En consecuencia, hubo durante los conflictos universitarios recientes, destrucción de estudios, de laboratorios y de instrumentos de investigación. Pero con preconceptos selectivos porque quienes sé proclamaban defensores de la nacionalidad, obturaban unos cauces de penetración cultural, tecnológica y científica, mientras les abrían amplias puertas a procedencias ideológicas que les fueran de su afecto.

Con faceta nueva, Jean Ladriére nos presenta las tres urgencias universitarias de hoy: Aunque por algunos conceptos -nos dice- la ciencia peculiar de acción no sea otra cosa que subcomponente de la cultura, en otro sentido se separa de ella y pasa a formar sistemas culturales autónomos que se oponen a la cultura total. Por esta razón nos hemos visto obligados a preguntarnos urgentemente sobre la interacción de ciencia y tecnología, por una parte, y el universo de la cultura, por otra. O, en otras palabras, a preguntarnos en qué forma tecnología y ciencia están afectando y afectarán el futuro de la cultura: ¿La están desintegrando progresivamente? ¿Están elaborando nuevas modalidades culturales?

Este urgente preguntarse corresponde a las tres urgencias enunciadas por Paul Ricoeur Interrogante critico sobre el futuro de la nacionalidad de la cultura, sobre la persona y sobre las decisiones políticas influidas por el dominio innegable de la ciencia tecnológica. Este dominio bien lo sabemos, se da en los países que generaron la ciencia y la técnica, y también en los países que la importan. La urgente pregunta tiene vigencia universal.

+ El Papa Paulo VI, en la encíclica El desarrollo de los Pueblos emitió la fórmula ración.- y salvadora: Que "haya diálogo centrado sobre el hombre y no sobre los productos o sobre la técnicas" Pues este diálogo "será fecundo si aporta a los pueblos que de él se beneficien 10 medios que lo eleven y lo espiritualicen". "Si los técnicos se hacen educadores, y si las enseñanza por ellos impartidas vienen marcadas por una cualidad espiritual y moral tan elevadas, que garanticen el desarrollo, no solamente económico sino también humano". 
CRÍTICA POLÍTICA CULTURAL NACIONALISTA
La necesidad del ejercicio consciente, racional, responsable da las tres urgencias universitarias constituye el núcleo de nuestra tercera reflexión, que ampliaremos en las tres reflexiones siguientes:

\section{Cuarto círculo de reflexión La conciencia crítica, investigación-docencia}

Es halagüeño percibir en la abundante literatura de nuestros días, proyectiva de la universidad hacia el futuro, la tendencia a depositar el acento prioritario de la educación sobre la persona racional y éticamente crítica de las actuales condiciones; defensora de sus propios valores nacionales pese al concierto abierto y pluralista de las culturas contemporáneas, y libre dentro del orden político que las personas concertadamente adopten.

+ Partiendo entonces de los enfoques racionales -no apasionados ni emotivos- de las tres urgencias que se le imponen, debe la Universidad esforzarse por hallar las fórmulas solutorias a reales o aparentes contradicciones o antinomias, perceptibles en los enunciados fundamentales de los modelos universitarios clásicos.

Tanto éstos como los estilos derivados de Universidad tratan de resolverlas con los recursos de que disponen, frente a situaciones sociales cambiadas y rápidamente cambiantes del mundo contemporáneo. Por ello el milenio que termina viene discurriendo sobre el legado de fórmulas universitarias novedosas que dejará al venidero, y no es extraño entonces que haya habido en la segunda mitad del siglo XX tantos intentos de reforma universitaria, y que no pocas piezas de la literatura educativa de hoy se anuncien con títulos como la universidad del mañana o la universidad en el siglo XXI. 


\subsection{Investigación unida a la docencia La Persona}

Casi todos los intentos de proyectiva universitaria incluyen la real u aparente antinomia: investigación (INV) o docencia (DOC). Toman en cuenta las prolongadas discusiones en torno a -i la Universidad del futuro debe situar su función académica sólo en la transmisión de los conocimientos; si extenderlas hasta la investigación e incremento del acervo cognoscitivo, o si ha de preferir aquellos métodos de pedagogía universitaria que hagan del aprendizaje un resultada de la actitud investigativa permanente.
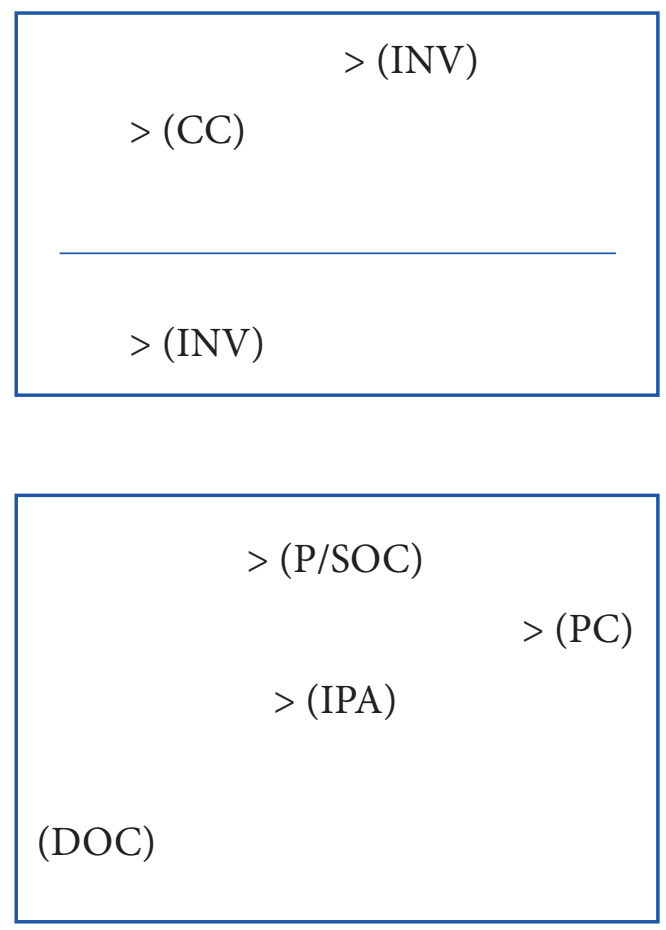

(1)

+ Si (1) esta real o aparente antinomia resuelve en favor de la Investigación (1 NI se erige en torno esta una nueva disyuntiva: Investigación de la Ciencia por la Ciencia (CC) o Investigación para beneficio de la Sociedad regida por la Persona (P/SOC). En este sentido, la Persona constituye el principal objetivo de la gestión educativa superior.

\section{(2)}

+ Si (2) la solución del dilema beneficia a Docencia (DOC) y al aprendizaje, también se prosigue a ulterior instancia: la Instrucción y el Pasivo Aprendizaje (IPA).o a Participación Activa (PA) de la persona en di proceso de aprender. Algo así como si es acción de asimilar el saber fuera un derivado natural y espontáneo del quehacer investigativo del estudiante por su contacto con el maestro.

En el primer caso sólo se logra una persona diseñada para preestablecida concepción. En el segundo, aun aceptando que la educación nunca debe obedecer a un proceso neutro y atélico, la Persona (P) se yergue de nuevo para constituir el objeto primario de educación superior. ¡Que la persona sea! Que la persona ise haga a sí misma! 
De manera que por toda vía se concluye en la necesidad de superar todo cuanto se oponga a la concertación de las actividades investigativas y docentes de la Universidad presente y futura, a fin que desde muy temprana edad se procure el desarrollo de la inteligencia recursiva y creativa por ser la Persona el agente de la investigación y señora y orientadora de la Ciencia (P/C).

Propósito que conlleva el imperativo ineludible de contar con una corporación universitaria -directivos, profesores y estudiantes-, toda ella conocedora de la naturaleza de la Universidad y de sus misiones; preparada -cada estamento en lo suyo- para el desempeño de sus respectivas funciones, y resuelta a elevar los niveles de calidad en sus múltiples aspectos. Es el reiterado problema de disponer de los óptimos recursos humanos exigidos por la misión educativa.

+ Si bien es cierto que los contratos de investigación que la Universidad signa con empresas oficiales o privadas, son aspectos que no deben desdeñarse, se piensa que no sólo en ellos debe fincar la Universidad su prestigio investigativo. Le es imprescindible crear el ambiente de investigación y búsqueda permanentes, en profesores y estudiantes, echando mano de los recursos que mantengan la simbiosis enriquecedora de investigación y docencia.

+ Para hacer posible esta alianza pedagógica de investigación-aprendizaje (mejor que investigación-docencia), todo el proceso educativo viene hoy, también el universitario, buscando alimentarse de los sistemas propios de la educación personalizante y de la investigación y aprendizaje interdisciplinario, ambos propicios para armar currículos cuyo contenido se aprehenda mediante vital y creativa experiencia de aprendizaje, conscientes, quienes enseñan y aprenden, del destino social y justo de la ciencia humana.

\subsection{La educación personalizada}

Los sistemas de educación personalizante desde los primeros niveles de la educación, van adquiriendo cada día mayor vigencia. Bien está que la Universidad se disponga para habérselas pon el nuevo estilo de universitarios que le vienen de los niveles primarios y secundarios, practicantes de estos nuevos sistemas educativos. 


\subsection{La interdisciplinariedad}

Por interdisciplinariedad se entiende la innata relación de ciencias, profesiones y especialidades, en procura de alguna forma de unidad de las ciencias; de currículos que concierten los diferentes dominios de la ciencia y los conocimientos humanos, y de soluciones adecuadas a los complejos problemas de la sociedad. Así entendida, la interdisciplinariedad no es sinónimo de omnisciencia ni de omniscientes. Se cuenta con las especializaciones y los especialistas porque si las tales y los tales existen, se hace necesario relacionarlos y concertarlos.

Con la interdisciplinariedad se intenta formar personas omnícomprensivas del espectro polifacético de las ciencias y los conocimientos, de manera que se supere el exclusivismo de las profesiones. La interdisciplinariedad consulta la situación actual de las profesiones, sometidas a continuos cambios de su identidad, obligados por las necesarias relaciones con otros dominios profesionales.

La formación interdisciplinaria, sin olvido de las ineludibles relaciones entre la Universidad y la organización técnica y científica del trabajo, producirá personas menos dependientes del mercado laboral, tan modificado hoy por el avance de la ciencia y del saber.

La interdisciplinariedad hace pensar que si la Universidad tiene disciplinas y profesiones, la sociedad abunda en problemas cuya solución exige el acuerdo interdisciplinario.

\subsection{Los currículos}

Quienes tienen a su cargo los montajes curriculares, deberán construirlos en forma que respondan bien a las instancias de la educación personalizante que forma universitarios creativos amantes de la investigación, y a cuanto demanda el esfuerzo interdisciplinario que capacita mejor para los amplios intereses intelectuales y en beneficio de la constante adecuación al campo del trabajo.

+ Concluye el cuarto círculo de reflexión: en el esfuerzo que se cumpla para aproximar la investigación a la docencia; unión estimu- 
lada por la educación personalizante y por las relaciones interdisciplinarias de los currículos. Todo lo cual conduce a lo que se debe entender por educación en lo superior y para lo superior, y ponerla en práctica.

\section{Quinto círculo de reflexión La conciencia política ¿Educación de todos o de pocos?}

El enflechamiento cuantitativo de la educación moderna, pero más la certeza de ser la educación derecho de todos y garantía del progreso y de la paz social, indican que la igualdad de oportunidades debe darse para todos, real y efectiva, supuesto el carácter selectivo de la educación superior.

\subsection{La educación permanente}

Por ello es cada vez más claro el deseo de concertar los sistemas formules con los no formales de la Educación permanente, siempre activa y actuante en las diversas situaciones que el hombre viva, y prolongada a todos los momentos de la existencia humana. La inteligencia, virtud de todos, es siempre perfectible y desarrollable. El conocimiento y la formación del ser humano no conocen límites.

Esta es la gran fuerza de los principios que rigen la educación en estimulante permanencia, deber ineludible de la Universidad hacia el futuro, enfrentada con la mis inminente expansión de los medios internéticos y virtuales.

\subsection{Los sistemas postsecundarios}

Toda sociedad bien organizada es funcional. Cada persona juega un papel en la vida. Si la sociedad es en cierta manera jerárquica, es porque debe haber diferencias de funciones que cada quien ejerce en el seno de la sociedad. No de estratos o clases enfrentadas para que la pugna se convierta en dinámica del desarrollo. Sino desempeños diferentes y concertados, requeridos por lodos, para vivir en sociedad armónica. 
De donde la urgencia de acertar en el diseño de modelos postsecundarios de la educación superior. Tarea investigativa de nuestro momento universitario, proyectado hacia el futuro.

Diseños los hay. Desde el siglo XIX el nivel superior de la educación se diversificó en diferentes especies institucionales: las Universidades, los Tecnológicos, las Instituciones de capacitación práctica, de modo y manera que terminado el nivel secundario de la educación, el estudiante ingrese al establecimiento de su agrado y cualidades, sin que por ello se le impida la eventualidad de posibles transferencias. Los diseños postsecundarios, si acertados, ayudarán a discernir en mejor forma las tareas peculiares de la Universidad y de las restantes instituciones -educativas y de otra naturaleza- conforme a la exigencia de profesiones y oficios por parte de la organización del trabajo.

\subsection{Extensión y servicio universitarios}

Volviendo a los principios de la educación permanente, y sacadas de ella todas sus implicaciones políticas y sociales, desde el siglo XIX, y hoy más, se viene pensando que si bien no todos han de ascender los últimos peldaños de la educación superior, la Universidad sí debe disponer los caminos para llegar a todos. Lo cual es garantía para la formación crítica, política y nacionalista del conglomerado social.

Consciente la Universidad de esta urgencia política y social, mejor establecerá sus órganos de servicio y extensión.

+ Educación de todos a lo largo de la vida y en todas las situaciones del ser humano y adecue la diversificación del nivel superior educativo, y acciones extensivas de sus beneficios, e la conclusión de este círculo de reflexión que, como el anterior, aporta soluciones prácticas.

De otra parte, gracias al esfuerzo que la universidad haga para, de manera no-formal asumir las responsabilidades de educación permanente, de extensión y de servicio, ella desformalizará sus procesos académicos, necesidad hoy muy sentida. 
Con sobrada razón se piensa que de la fusión de los sistemas formales, no-formales e in-formales de la educación, llegaremos a estilos de administración académica menos elitista y más al alcance de la masa social.

La educación permanente es otro perfil de la educación en lo superior y para lo superior.

\section{Sexto círculo de reflexión: La conciencia nacional y cultural Pluralismo cultural. La tecnología}

El ser humano nace en la historia. Los conglomerados culturales y nacionales tienen su historia, hacen su historia, no pueden prescindir de sus ancestros y tradiciones.

Se creyera que esto pugna con el hecho contemporáneo del pluralismo cultural. Hoy todo se mete en nuestras vidas y naciones, procedente de todas las culturas y recodos del mundo. Las sociedades no pueden cerrarse, pero tampoco abrirse para mengua de la nacionalidad y la cultura propia.

Las manifestaciones artísticas y culturales -música, pintura, danzas, folklor...- discurren de pueblo a pueblo y de nacionalidad a nacionalidad. Nadie lo objeta. Se lo fomenta. En la ciencia, que es universal, no se ve el peligro de transferencias culturales dañinas. Es de esperar que no se vuelva a hablar en el futuro de física aria o de matemática soviética. Es en la tecnología, la cara visible de la ciencia, donde se descubre al invasor de los cuadros culturales y el artefacto deformador de las nacionalidades.

De nuevo, la vigorosa formación de la persona y el desarrollo de sus posibilidades creativas de arte, ciencia y tecnologías, se torna, con mayor razón, en quehacer imprescindible de la Universidad hacia el futuro, que no puede desdecir de cuanto a ella le compete en formación de una auténtica conciencia cultural democrática y nacional. Conciencia abierta a las culturas de los pueblos en procura de la paz universal. 
La Universidad ha de permanecer vigilante de los valores trascendentales y temporales del ser humano, y no le es lícito escatimar esfuerzos para conocer el universo que la rodea. Cada una es parte de un gran todo, y deben ser constantes los esfuerzos de la Universidad por adentrarse en la educación comparada. Nada le es ni le será en el futuro a la Universidad, distante y ajeno.

La tecnología en todas sus dimensiones es ya y seguirá siendo parte de la cultura de los pueblos y tarea de la Universidad. No debe pensarse que la tecnología, por sí misma, sea deshumanizante: es humana y debe ser humanizable. Este es un deber insoslayable de la Universidad hacia el futuro.

Y con mayor razón si se piensa que de los avances tecnológicos dependen en gran manera la armonía y los equilibrios ecológicos del medio ambiente físico, sustento de la vida en el planeta y legado que las actuales generaciones deben salvar como un derecho que tendrá la humanidad del futuro. Concierto de aire, agua, suelo y energía, el complejo biológico, si desarmonizado, es difícilmente restaurable.

+ Vigorosa formación de la persona en los valores nacionales y culturales propios: con ojos abiertos a la racional y cordial comprensión de los valores de la cultura, y capacitada en sus facultades para conducirse y conducir una vida y un mundo de cambios y desarrollo más acelerados e imprevisibles, son los motivos de este sexto círculo de reflexión, para procurar la paz entre los pueblos.

\section{Séptimo y último círculo de reflexión: La autonomía}

La educación es un hecho individual y también social. Por la educación, el carácter de la comunidad se imprime en cada uno de sus miembros individuales. En el zoon politikon o ser político en concepto de Aristóteles, fuente de toda acción y de toda conducta.

De la educación depende el crecimiento de la sociedad, y no sólo del individuo. La educación decide el destino exterior y la estructura y espiritual del grupo humano; 
+ Educar es deber de la sociedad. El derecho inalienable a la educación radica en la célula social que es la familia. Las instituciones sociales educativas y el Estado suplen subsidiariamente las limitaciones y deficiencias familiares en los procesos educativos, de modo particular en cuanto concierne a la formación científica y profesional.

+ El Estado, y en concreto los gobiernos, son tutela y defensa de la sociedad, y velan por la distribución justa del beneficio educativo. Suplen. No son por sí mismo educadores pero sí canalizadores sabios de todos los esfuerzos educativos.

Por su naturaleza el Estado no es poseedor del poder epistemológico del saber, sí de la autoridad deontológica que oriente todo hacía la justicia, la paz y la armonía en la sociedad.

+ A la educación en general y a la Universidad les corresponde la gestión imaginativa y creativa de las acciones propias de la educación. En vano diría el Estado fomentar e impulsar la educación creativa y el desarrollo de la inteligencia humana, si a esa misma inteligencia se empeña en conducirla por cauces fijos y con torbellino de normas limitantes y entorpecedoras.

Deje a las instituciones del saber, oficiales o privadas, acostumbrarse a buscar y encontrar sus formas de organización y de acción eficaz.

Al Estado lo asisten el derecho y la obligación de ejercer suprema vigilancia y tutela de las empresas educativas de la sociedad, pero de manera que la erradicación de los abusos no conduzca a impedir la buena marcha de los buenos usos establecidos. Abusus non tollin usum, dijo la sabiduría jurídica de los romanos.

+ A las instituciones sociales, oficiales o privadas, especialmente a las de carácter educativo y científico, les compete fortalecer y secundar las acciones constructivas del Estado. La concertación de esfuerzos y políticas entre el Estado y las instituciones educativas es tarea ineludible.

+ Los sistemas educativos, y mucho más la Universidad, deberán empeñarse en la concepción de estructuras administrativas y de administración de lo académico, flexibles y adecuadas en cada momento a las exigencias de nuestros tiempos, y en el ejercicio 
pulcro y electivo de los recursos financieros que del Estado y la sociedad perciban para el desempeño de funciones.

+ Quizás por la proximidad del siglo XXI y el tercer milenio de la era cristiana, y cuando la humanidad se rehacía del segundo desastre bélico mundial del siglo XX, se encumbraron las manías agoreras y las aficiones predictivas siempre actuantes en la inquisitiva curiosidad humana.

Le debemos a Gastón Berger (1950) haber vestido la palabra prospectiva -ver desde lejos y hacía lo lejos- con el significado ansioso de imaginarle futuros racionales y posibles -futuribles- a una sociedad, asunto o situación. Por coincidencia o causa, el mencionado filósofo francés escribe cuando madura la más reciente cosecha de teorías sobre la planeación empresarial. 3/

Semánticamente, la palabra prospectiva está emparentada con perspectiva o ver a través de algo. Artistas del Renacimiento -Uccello, Masaccio, Mantegna, Leonardo...- se ingeniaron las leyes de cómo remedar técnicamente, sobre plano traslúcido, las reducciones e inclinaciones ópticas del objeto o volumen real y de su espacio circundante, motivos de la curiosidad estética, o de producir y dibujar las formas concebidas pero aún ocultas en la imaginación artística.

Ambos términos, prospectiva y perspectiva, confluyen en la idea actuosa de pro-yectar o lanzar líneas, trazas, ideas, anhelos de algo aún inexistente. Algo así como pre-ver lo futuro o pre-hacerlo mediante la pro-yección o prolongación de tendencias más o menos constantes, respecto a las cuales se pueda obrar en por lo menos los siguientes modos que sintetizamos en los verbos: mantenerlas y fortalecerlas si son de nuestro agrado, modificarlas en lo conveniente y necesario, crear nuevas con ánimo decidido, y aun cancelar las indeseables.

Las tendencias actuantes en el pasado y en el presente, constituyen los factores del futuro proyectado y deseado, los cuales, a su vez, suponen sus sujetos activos o actores. En igual forma, las tendencias creadas de propósito serán factores del futuro que se anhela, exigentes de los actores que las hagan efectivas.

Pero los actores, como las tendencias, pueden obrar con determinadas intenciones o enfoques que reducidos a su mínima diversidad, no exclusiva ni excluyente, son científicos, técnicos 
y tecnológicos, garantizables en razón de la fijeza de las ciencias exactas. Otros enfoques, en cambio, no fácilmente predecibles, dependen en gran manera de condiciones geográficas, físicas y humanas, del entorno cultural, de lo social y de las cambiantes situaciones políticas y económicas.

En una o en otra forma y con mayor o menor aporte, estos enfoques deciden la naturaleza Je las hoy llamadas escuelas de prospectiva, de proyectiva, o de futurología si así se las quiere denominar: Que si la francesa de Berger, 1957 y otros autores. Que la soviética desprendida del materialismo histórico y la pretendida física social. O que la checa nacida en la euforia de la Primavera de Praga, 1965 a 1968. Otras más, y las economicistas de Norteamérica. El Instituto Europeo de la Prospectiva. El Club de Roma...

Cualquier enfo les es complejo a todas las escuelas en el siempre ilusorio empeño de mirar desde lejos y hacia adelante, o de configurar a las inmediatas, aquí y ahora, lo fingido. Las tendencias, actuantes o creadas, se interceptan en el pro-nóstico -conocer de antemano- de los posibles espacios o futuros escenarios que se espera han de rodear la anhelada y concreta ficción. El saber lo que se quiere entra siempre en conflicto con el poder hacer.

+ De regreso a nuestro asunto, la prospectiva universitaria, el sentido común nos insinúa a la primera el esfuerzo de pro-yectar para el intento de pre-ver-no de pre-decir con apoyo de cartas o esferas de cristal-, desde nuestro actual lejos o distancia. La universidad del futuro en sus futuros escenarios, como imaginándola en acuerdo con sus actuales tendencias históricas, ora fortalecidas o modificadas según nuestros deseos, suprimiendo cuanto se juzga ser inconveniente, o creando hacendosos nuevos impulsos con el propósito de configurarle a la universidad venturoso porvenir.

Así entendida, la prospectiva universitaria no corre en contra vía de la perspectiva y la proyección. Es cierto que el volumen o forma de la universidad futura aún no existe, como tampoco sus futuros espacios o escenarios circundantes. Pero en el plano pictórico de nuestra mente inciden y están presentes las tendencias históricas, recientes y actuales de la universidad Las tenemos bien conocidas gracias a la somera revisión documental y bibliográfica que arriba (Intr. 2) dejamos colectada.

Esas tendencias, actuantes en nuestras mentes, nos advierten de sus fortalezas y sus direcciones. De nosotros depende, si nos 
placen, fortalecerlas y perfeccionarlas. Si necesario, rectificarlas. O derogar o suprimir las perjudiciales. Y mejor si por nuestra propia industria, iniciativa y tesón, a la universidad le creamos deseables y saludables pro-yecciones. Reiteramos así lo ya afirmado: la forma o futuro volumen de la universidad y de sus espacios o deseables escenarios, es presente hechura de nuestras intenciones y conatos para que el futuro inmediato no sea exacto sinónimo del presente. Podemos desde ahora, con apoyo en nuestra imaginación artística, dibujar ya la perspectiva volumétrica y espacial de la universidad en el futuro.

La historia y el presente de la universidad y sus tendencias siguen diciéndonos que se trata de una institución orientada a la formación de la persona y al desarrollo y difusión de la ciencia para el servicio a la sociedad, y movida en sus acciones por la triple y conjugada conciencia crítica, política y cultural. Prospectiva, perspectiva, proyección o prognosis, no pueden apartarse de estos predeterminantes, porque estaríamos inventando sabe Dios qué forma o volumen de imposibles configuración y realidad.

+ En cuanto al espacio o escenario prospectable, dibujable o proyectahle, habría mucho qué decir, tenidos en cuenta los enfoques que dejamos arriba bocetados.

Pero, simplificando al máximo la palabra g/obalización, hoy tan mentada, parece resumir bien las múltiples dimensiones del escenario futuro. Según Yoshikazu Sakamoto, hay dos dimensiones dominantes de la globalización: la internacionalización y la democratización del mundo. La primera, internacionalización, se superpone a los conceptos de sociedad, región, nación y estado: y la segunda, democratización, se cruza por entre los de clase, raza, religión, etnia, género, edad..., que han apuntado y apuntan al complejo concepto de sociedad.

Lo internacional es concepto que nace para señalar las relaciones entre los estados-nación, plenamente condensados desde el siglo XIX y fraguados en los principios soberanos de la cultura nacional, la organización política, el territorio, la posesión, manejo y uso de los recursos naturales y del orden económico. Este último principio de las nacionalidades es destacable porque bajo su imperio empezaron a circular los conceptos de trans-nacionalidad, de multi-nacionalidad y de supra-nacionalidad. 
A las naciones, en sus relaciones internacionales y en los acuerdos y relaciones de esta naturaleza, históricamente las venían rigiendo los antedichos principios constitutivos, y la fisonomía política e interna y el principio cultural de cada nación dominaban sobre lo económico P]E. En lo transnacional y lo multinacional, formas de relación obligadas por lo empresarial y económico, la cultura y la fisonomía política nacional parecen haber aceptado ponerse en plan de igualdad con lo económico para hablar de tú a tú: P] [E. En lo supranacional, concepto más insinuante de la globalización, la economía se superpone a los principios de la nacionalidad soberana: E]P.

Al ritmo de estos diferentes arbitrios -destaquemos de nuevo el económico-, y pese a la varia interpretación de los derechos humanos universales, corre la suerte de la tan deseada solidaridad entre los pueblos, hoy entretejidos, en un mundo que se achica como "aldea global", por la interpenetración de las culturas, incluida la deportiva, por el proteccionismo, por las abultadas migraciones, por el emparejamiento de la trasferencia tecnológica, por los satélites de la comunicación y la informática, ya fácilmente planetarias y domésticas, por la trans-multi y supra-nacionalización de las empresas que modifican y desestabilizan la organización y el ejercicio del trabajo, por la conciencia universalizada del problema ecológico, y por tantos otros factores, como la violencia y el crimen organizado -el narcotráfico- que exigen ya una justicia supranacional, globalizada.

Todas estas dimensiones prenuncian el escenario futuro y ponen en bretes, según algunos, el futuro de los estados-nación. "Ya es común decir en el mundo contemporáneo -afirma Sakamotoque ningún estado 'soberano' puede actuar aislado de los restantes o dejándolos de lado porque se causaría a sí mismo un gran daño. La 'impermeabilidad' que caracterizó el modelo clásico del estado soberano, está amenazada", 4

Ante tan complejo escenario, la Universidad, universal por definición, hacia el futuro debe fortalecer su capacidad de adaptación a cambios que ya están en marcha y a los mayores que vendrán. Mas, para no destruirse en este obligante acople, a la Universidad le corresponde, afianzar su calidad: unidad, veracidad y bondad institucionales. 5/ Imperativos internos dirigidos por claros principios que resultan tanto más ineludibles si se retoma en cuenta la tripleta de misiones y funciones de la Universidad: la persona formada en lo superior y para lo superior y gestora de la 
ciencia para ser servicio y pauta -no sólo reflejo- de la sociedad. A tan alto ideal de formación hay que tender teniendo en cuenta la unidad ontológica de las disciplinas, la objetiva unidad del mundo, y la internacionalización de la vida social, imperativos de la interdisciplinariedad.

+ Si la Universidad está llamada a ser fuente, vigor y conductora de la cultura y los conocimientos regidos por la verdad, debe ella, para despertar confianza, respetarse a sí misma concertar y concertarse con todos los ordenamientos culturales, sociales, políticos, económicos técnicos que conduzcan al verdadero desarrollo, idea en muy variadas formas está ligada diferentes concepciones filosóficas de la historia.

Para los antiguos, no muy percatados del pasado histórico y de la inmensidad del orbe, la concepción de la historia fue reincidente sobre sí misma a la manera de círculo perfecto. Otros la han pensado como en altibajos, o aun descendente porque piensan que todo pasado fue mejor. O siempre ascendente a la manera de espiral que se empina pasando siempre vecina a sí misma, lo cual explica los renacimientos consignados por los historiadores. 6/

La historia como desarrollo indefinido fue, según afirmación de J.B. Bury en 1920, el "ídolo del sig/o"XIX. 7/ Quizá no presentía el autor el declive financiero subsiguiente ni el desastre bélico que culminó en 1945. Hoy, el cese de la Guerra fría; el auge de las expresiones copulativas Ciencia \&Tecnología e Investigación \& Desarrollo 8/, y el anuncio de la sociedad del conocimiento, vale decir, del trabajo intelectual elevado por encima de la disponibilidad de recursos naturales como origen de la riqueza de las naciones, son factores que empujan de nuevo la marcha del desarrollo. 9/

Pero, al mismo tiempo, las zonas de paz en contraste con las de violencia y luchas fratricidas; el crecimiento de la salud junto a inmensas poblaciones endémicas y desposeídas, y la angustia mundial por el deterioro y agotamiento de las fuentes energéticas, le han impuesto al concepto de desarrollo el propósito compensatorio y optimista de hacerlo sostenible.

Esta expresión adjetivante parece haberse usado por primera vez allá por los años ochenta en la Declaración de Estocolmo sobre el Medio Humano; se la reitera en Informes y Asambleas mundiales, y no deja de asomar su rostro promisorio en muchas de nuestras proclamas seculares. 
El desarrollo sostenible no es una noción fija. Quizás se nos antoja ambigua: ¿Qué es lo sostenible para que el desarrollo también lo sea? La noción puede parecernos reducida a sostener las condiciones indispensables para conservar la vida en el planeta, lo cual le otorgaría responsabilidad prioritaria, si no exclusiva, a las ciencias naturales, Pero la UNESCO, en 1997, amplió la visión: "La sostenibilidad requiere un equilibrio dinámico entre muchos factores, incluidas las exigencias sociales, culturales, económicas de la humanidad, y (no sólo) la urgencia imperiosa de salvaguardar el entorno natural que la aposenta". 10/

En otros términos, que el desarrollo sostenible debe ser enarbolado sobre el avance armónico de todos los universales de la cultura 11/ para que el desarrollo de los pueblos llegue a ser "el nuevo nombre de la paz". No se crea entonces que el legítimo desarrollo ha de sostenerse hacia el futuro sobre el monolito tecno-financiero y exento de todo compromiso con la ética y la justicia.

Es claro que el desarrollo, en el sentido de creación, avance y posesión de la tecnología, no es igual en toda la superficie del planeta. Latinoamérica y sus universidades ocupan posiciones dependientes. Más si todas las universidades están llamadas a formar a la persona en las alturas de las ciencias regidas por la causa de la verdad y de la justicia, de la persona depende que sobrevolados los óbices, ella acelere la marcha del auténtico desarrollo de nuestras naciones.

El desarrollo, ya lo insinuamos, es inseparable de las concepciones que se tengan de la historia. Pero cualquiera que sea la nuestra personal, y más si enfilada hacia el alcance de una meta deseada, no olvidemos que toda la historia discurre bajo la mirada providente de Dios, principio y fin de todas las cosas, de todas las vidas, y del proceso escatológico de nuestra historia de salvación.

+ Con los precedentes supuestos cuenta la Autonomía de la Universidad. Autonomía fundada, en último término, sobre tas libertades del espíritu pensante y el poder del saber. Pero la universidad ha de advertir que así la autonomía le sea derecho connatural, debe merecerla mediante el desempeño responsable de tos ejercicios autónomos. La autonomía, que es libertad de acción, sin responsabilidad se convierte en libertinaje. Consciente, en cambio, la Universidad, del serio compromiso que le compete de educar al hombre, a la nación y a la sociedad, merecerá el reconocimiento autónomo de sus funciones educativas, si procede con humanismo y pensamiento.

Y si la Universidad es pensamiento y humanismo, la que nosotros deseamos y gestamos no podrá ser construida sin inteligencia y libertad.

Pero sólo el que lleva en la mente y en el corazón la idea auténtica de Universidad, podrá pensarla libremente y realizarla con máxima eficacia.

+ Este es el último círculo de reflexión: Libertad creativa y responsable en un mundo de más amplias y complejas dimensiones.

+ LOS siguientes ESQUEMAS correlacionan los siete Círculos de Reflexión con las Conferencias y temas del Simposio Permanente sobre la Universidad. 


\begin{tabular}{|c|c|c|}
\hline $\begin{array}{l}\text { CÍRCULOS } \\
\text { DE } \\
\text { REFLEXIÓN }\end{array}$ & CONFERENCIAS & TEMAS DE LOS CÍRCULOS \\
\hline \multirow[t]{15}{*}{ (l) } & & LOS MODELOS UNIVERSITARIOS \\
\hline & $\|$ & + Las universidades desde 1800 \\
\hline & $\|, \mathrm{VII}$ y VIII & $\begin{array}{l}\text { + Misiones, Notas y Funciones de la Universidad } \\
\text {-En el Medioevo } \\
\text {-En el Renacimiento } \\
\text {-En el Nuevo Mundo }\end{array}$ \\
\hline & $X I$ & + Los modelos universitarios \\
\hline & XII & -Napoleónico \\
\hline & XIII & -Alemán \\
\hline & XIV & -Británico \\
\hline & $X V$ & -Norteamericano \\
\hline & $X V I$ & -Soviético (maoista) \\
\hline & XVII y XVIII & -Latinoamérica \\
\hline & $X I$ & $\begin{array}{l}\text { + Las Universidades idea y las Universidades } \\
\text { función }\end{array}$ \\
\hline & $\mathrm{VI}$ & + La educación para lo superior y en lo superior \\
\hline & XXIV & + La formación general \\
\hline & $X X V$ & + La educación personalizada \\
\hline & XXIII & + Más allá del currículo \\
\hline
\end{tabular}

(II)

FILOSOFÍAS DE LA UNIVERSIDAD. LA PERSONA

III, IV y V

+ Filosofía y Ciencia

+ Filosofía de la Universidad

$\begin{array}{ll}\text { XIII } & \text {-U. Alemana } \\ \text { XIV } & -U \text {. Británica } \\ \text { XV } & -U \text {. Norteamericana } \\ \text { X Y XX } & + \text { Las Universidades y la Ciencia } \\ \text { VI } & + \text { La Educación para lo superior y en lo Superior } \\ \text { XXIII } & - \text { Los aprenderes }\end{array}$




\begin{tabular}{|c|c|c|}
\hline & V & +Ciencia, Arte. Técnica y Cultura \\
\hline & XXIII & + El Currículo \\
\hline \multirow[t]{3}{*}{ (III) } & & URGENCIAS DE LA CONCIENCIA UNIVERSITARIA \\
\hline & $X I$ y XL & + Urgencias universitarias \\
\hline & $X I, X X X V I I$ & $\begin{array}{l}\text { + Los movimientos estudiantiles modernos } \\
\text { y contemporáneos }\end{array}$ \\
\hline
\end{tabular}

\begin{tabular}{|c|c|c|}
\hline (IV) & & LA URGENCIA CRÍTICA \\
\hline & & + La Investigación \\
\hline & $\|$ & -En la Universidad medieval \\
\hline & $X y X X$ & -A partir de la revolución científica \\
\hline & XII a XVIII & -En los diferentes modelos universitarios \\
\hline & XIX & + Formas y métodos de investigación \\
\hline & IX & + El Seminario investigativo \\
\hline & $X X V I$ & $\begin{array}{l}\text { + Administración de la Investigación. } \\
\text { Investigación y Docencia. La Creatividad. }\end{array}$ \\
\hline & XXV y XXIV & $\begin{array}{l}\text { + La Educación personalizada y la Formación Gene- } \\
\text { ral }\end{array}$ \\
\hline & XXIII & + Los Currículos \\
\hline & $\mathrm{XVI}$ & + La Escuela nueva \\
\hline & $x X$ & $\begin{array}{l}\text { + La Interdisciplinariedad } \\
\text { + Los Currículos }\end{array}$ \\
\hline & $\|$ & -En la U. Medieval \\
\hline & VIII & -A partir del Renacimiento \\
\hline & XXIII & -Administración y evaluación del currículo \\
\hline & XXIX & -En la Educación Permanente \\
\hline & $X X X \mid$ & -En los Postgrados \\
\hline & XXXV & + Educación e Informática \\
\hline
\end{tabular}

(V)

LA URGENCIA POLIITICA

XXIX 


\begin{tabular}{|c|c|}
\hline XXIX & + La Educación Permanente y no formal \\
\hline VI & + La Educación para lo superior y en lo superior \\
\hline$X X X$ & + Los sistemas postsecundarios \\
\hline$X X X \mid$ & + Los títulos y su función social \\
\hline$\|$ & -En la U. Medieval \\
\hline$X X X \mid$ & -En la Edad moderna y contemporánea \\
\hline$X X I X$ & -En la Educación permanente \\
\hline III a V & + Ciencia y Sociedad \\
\hline XXIX & + Educación, Extensión, Servicio \\
\hline$X X X \mid$ y $X X X$ & + Educación y Trabajo \\
\hline XXIII & + El currículo \\
\hline XXXIII & + La Corporación Universitaria hoy \\
\hline$X X I$ y XXII & + Las Estructuras \\
\hline XXXIV & + La planta física universitaria \\
\hline
\end{tabular}

$\begin{array}{ll} & \text { CONCIENCIA DE NACIONALIDAD } \\ \quad V & + \text { Ciencia, Arte, Técnica y Cultura } \\ X X & + \text { La Interdisciplinariedad } \\ X X X & + \text { Los Sistemas postsecundarios } \\ X X I X & + \text { La Educación permanente } \\ \text { VI, XXX Y XXIV } & + \text { La Educación para lo superior y en lo superior, y la } \\ & \text { Formación general }\end{array}$

\begin{tabular}{|c|c|c|}
\hline (VII) & & LA AUTONOMÍA \\
\hline & & + La Autonomía \\
\hline & I, II & -En la U. medieval \\
\hline & VIII & -En el Renacimiento \\
\hline & $X I I$ a XVIII & -En los modelos universitarios \\
\hline & XXXVI & + La Autonomía hoy \\
\hline & $X X X$ y XXVII & $\begin{array}{l}\text { + La autonomía en los modelos postsecundarios } \\
\text { + Organización universitaria general }\end{array}$ \\
\hline & $X X \mid$ & -Burocrática \\
\hline
\end{tabular}


6f Universidad del Azuay

\begin{tabular}{|c|c|}
\hline$X X \|$ y $X X$ & -Estructuras académicas \\
\hline$\|y X X\|$ & + Unidad institucional \\
\hline $\begin{array}{l}X X V I I, X X \bigvee I I I y \\
X X X \|\end{array}$ & + La planeación y la Evaluación \\
\hline$X X X V I I I$ a XL & + Constitución, Estado, Legislación y Autonomía \\
\hline$X X X V I$ & -Visión general \\
\hline$X V I I I$ y XXXVIII & -En Latinoamérica \\
\hline XXXIX y XL & -En Colombia \\
\hline $\mathrm{XLI}$ & + Prospectiva universitaria \\
\hline
\end{tabular}




\section{BIBLIOGRAFIA Y NOTAS}

-Staufer, Thomas, Edited by. Competition and Cooperation in American Higher Education. American Council on Education. Wash., 1981.

-Staufer, Thomas, Edited by, Quality: Higher Education's principal challenge, American Council on Education.

-Gulerpe, Universidade onlem, hoje oniannha. IX Reuniao do Gulerpe, Brazilia, Brasil, 1980.

-Peñalver, Luis Manuel; Garibay, Luis y Soria, Oscar, Situación y Perspectivas de la Educación Superior en América Latina. LAUP. Costa Rica, 1981.

-Escotet. Miguel. Planificación utópica y realidad. Enfrentamientos al devenir del aprendizaje en el siglo XXI. Revista Universitas 2000. 1982.

-Ortiz Amaya, Jorge. Educar para el año 2000. Tercer Mundo, Bogotá, 1982.

-ICFES. Prospectiva de la educación Superior. Bogotá, 1984.

-Mariin, W.B. Estrategia para la Reforma de la Educación Superior. Paidós, Buenos Aires, 1971.

-Mays Vallenilla. Ernesto. Arquetipos e Ideales de la Educación. Clase magistral. Universidad Simón Bolívar. Caracas 1971.

-Carrier, Ilervé, L'Université entre l'enseignement et la liberté. Presses de l'Université Gregorienne, Roma, 1972.

-Niblett, Roy W, and Butts, R. Freeman, Editors. Universities facing the Future. Jossey Bass, 1972.

-Ashby, Eric. The Structure of Higher Education: A World view. ICED. Occasional Paper. No. 6 N.Y., 1973.

-Birembaum, William. Hacia una nueva Universidad. Editorial Pleamar, Buenos Aires, 1975.

-Carrier, Hervé. Misión de la Universidad en la sociedad del futuro. Revista Universidades, UDUAL, No. 6. 1975. 
-Piaget, Jean. A dónde va la Educación. Colección Hay que saber. Editorial Teide. S.A.. 1975.

-Schabhut, Judilh (Edited by). The Past, Present, and Future of American Higher Education. 1976.

-Carrier, Hervé. Misión futura de la Universidad. Alheneo, Buenos Aires, 1977. Ben-David, Joseph. Trends in American Higher Education. The University of Chicago Press. 1972.

-Thomas, Jean. Les Grands Problémes de l'Éducation dans le Monde. UNESCO/PUF, 1975.

-Aranguren, José Luis. El futuro de la Universidad y otras Polémicas. Taurus, 1973.

-Quelle Université pour demain? En revista Problémes Politiques el Sociaux, número 542. IX. 1986.

-Mosquera Mesa. Ricardo. La Universidad ante los retos del futuro. (Sobre la Universidad Nacional de Colombia). Empresa Editorial Universidad Nacional de Colombia, 1989.

Sobre la Educación Comparada, ver: Noah, Harold J. and Eckstein, Max A. Toward a Science of Comparative Education. The MacMillan Co., 1969.

-Márquez, Ángel Diego. 